The use of hybrids becomes a significant feature of new medical electronic developments. Patient surveillance systems need to be portable, preferably small in size and weight and to operate off battery supplies. These features must be achieved with a high level of reliability, aspects which can readily be met by hybrid circuits.

A classic use of the hybrid circuit is the implanted heart pacemaker, shown in Fig. 5. Thin film and thick film technologies are combined to give optimum electronic and reliability of performance in this vital component.

\section{Summary}

A range of technologies has been developed to meet the requirements of the professional markets, where high performance, i.e., small size, environmental range, reliability etc., are key features. Gold features extensively in all of the products; in thin and thick film metallisations, in the conductive epoxies and solders, the wire used for making component interconnections and as a final coating of the total package. In all cases the presence of gold assists in the fabrication and subsequent performance of the microelectronic assemblies.

\section{References}

1 E. E. Smith and S. G. Ayling, Sputtered Dielectric Capacitors, 1962 Electronic Components Conference, Washington, U.S.A.

2 S. G. Ayling, T. A. Askwith and M. Tarr, The Manufacture of Close Tolerance Miniature Silica Film Dielectric Capacitors, Inter-Nepcon 1971

3 R. G. Finch, Gold in Thick Film Hybrid Microelectronics, Gold Bulletin, 1972, 5, (2), 26

4 W. A. Crosland and L. Hailes, Thick Film Conductor Adhesion Reliability, Solid State Technol., 1971, 42

5 P. C. G. Nolan, Resin Attachment of Semiconductor Dice on to Film Circuits, Microelectrics and Reliability, 1973, 12, pp. 235-241

\title{
A New Gold Metallisation System for Beam Lead Technology
}

Beam lead technology, developed by Bell Telephone laboratories in 1966, has permitted the fabrication of high frequency semiconductor devices and integrated circuits with very low parasitic capacitance as well as improved resistance to severe environments such as corrosive atmospheres or high acceleration.

The novel features of the technology were:

(a) the replacement of aluminium metallisation, with its attendant problems of junction degradation, corrosion and electromigration, by gold metallisation;

(b) the development of an etching process which permits the isolation of devices yet allows them to be interconnected by the "beam leads", cantilevers of electroplated gold which extend beyond the edges of the device.

Widespread adoption of the technology has, to some extent, been limited by the complexity of the operations involved, with the consequence of a relatively poor yield in production.

In a development now reported by Yoshiaki Nakamura of the Nippon Electric Co., Tokyo, a layer of chromium silicide is substituted for the original layer of platinum silicide used to make ohmic contact to the silicon (Nippon Electric Co. Research $\mathcal{E}$ Development, $1973,(31), 64-71)$. Another feature of the new process is that the surface of a subsequent layer of chromium is "passivated" by buffing with a moistened cotton

The improved electrodeposited gold contact fingers on an integrated circuit made by Nippon Electric. The new process permits the manufacture of beam leads using only two vacuum deposition stages instead of the three normally required ball. This treatment is reported to produce a hydrophobic surface on the exposed metal which prevents the adherence of gold during electroplating, and also to improve the adhesion between the electroplated gold and the platinum contact fingers. For this reason it is possible to increase the thickness of gold plating on the contact fingers with a consequent improvement in the high frequency gain of the devices.

It is possible entirely to dispense with one stage of vacuum processing, thus improving the yield from the production process. It is also claimed that the substitution of chromium silicide for platinum silicide results in a lower and more stable contact resistance. It is premature to decide whether improved yields will be achieved when the new system enters bulk production and whether the improved ageing characteristics will actually result in higher reliability, but it is a most interesting development that will be of widespread application.

G. J. H.

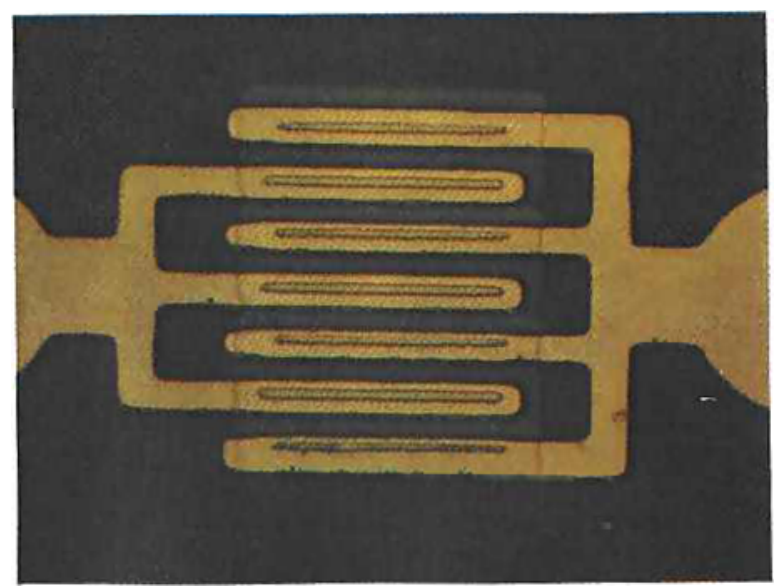

